(C) Elsevier/INRA

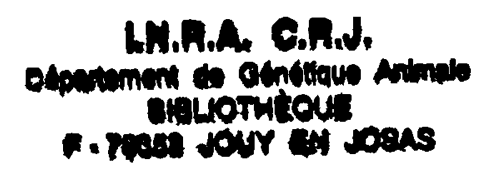

\title{
The gonadal histology of triploid chicken (Gallus domesticus) embryos
}

\author{
GA Bonaminio ${ }^{1 *}$, NS Fechheimer ${ }^{2,3 \dagger}$ \\ 1 Department of Molecular Genetics, The Ohio State University \\ Columbus, $\mathrm{OH}$; \\ ${ }^{2}$ Department of Dairy Science, The Ohio State University, \\ Columbus, $\mathrm{OH}$; \\ 3 Department of Poultry Science, The Ohio State University, \\ 2027 Coffey Rd, Columbus, OH 43210, USA
}

(Received 4 May 1992; accepted 2 February 1993)

Summary - Gonadal histological analysis was conducted on 7 pure triploid White Leghorn chicken embryos and $12 \mathrm{n} / 3 \mathrm{n}$ chimera at d 13 of incubation. Triploid embryos with sex chromosome complements ZZZ and ZWW exhibited gonadal organization consistent with that of normal diploid embryos while that of the ZZW triploid embryo was consistent with adult intersex birds. The morphology of the testes of the $5 \mathrm{ZZZ}$ triploids resembled that of normal $\mathrm{ZZ}$ males. The right and left ovaries of the ZWW triploid embryo were similar histologically to those of normal diploid ZW females. The intersex ZZW triploid and $\mathrm{ZW} / \mathrm{ZZW}$ chimera exhibited normal left ovarian organization but the right ovaries contained testis-like structures, similar to the reported histology of right ovaries in adult ZZW birds. The deviation of the observed numbers of each type of triploid embryos at $d$ 13 of incubation from the expected number based on previous observations of embryos at 16 to $18 \mathrm{~h}$ of incubation suggests differential mortality for the 3 types of triploid embryos.

triploid / chicken / gonad / intersex

Résumé - L'histologie des gonades d'embryons triplö̈des de poulet. L'analyse histologique des gonades a porté sur 7 embryons de poulet Leghorn blanche purs triploïdes, et 1 chimère $2 n / 3 n$ au $13^{e}$ jour d'incubation. Les embryons triploïdes avec des compléments chromosomiques sexuels $Z Z Z$ et $Z W W$ manifestaient une organisation gonadique analogue à celle d'embryons diploïdes normaux, alors que celles des embryons triploïdes $Z Z W$ était analogue à celle d'oiseaux adultes intersexués. La morphologie des testicules des 5 triploïdes $Z Z Z$ ressemblait à celle de mâles $Z Z$ normaux. Les ovaires droits et gauches de l'embryon triploïde $Z W W$ étaient similaires histologiquement à ceux de femelles diploïdes

\footnotetext{
* Correspondence and reprints
} 
normales $Z W$. Les triploïdes intersexués et la chimère $Z W / Z Z W$ montraient une organisation normale des ovaires gauches, mais les ovaires droits contenaient des structures de type testiculaire similaires à l'histologie connue des ovaires droits d'adultes $Z Z W$. L'écart entre les nombres observés de chaque type de triploïde au $13^{\text {ge }}$ jour d'incubation et le nombre attendu d'après des observations précédentes d'embryons entre 16 et 18 h d'incubation indique des différences de mortalité entre les 3 types d'embryons triploïdes.

triploïde / poulet / gonade / intersexué

\section{INTRODUCTION}

In chicken embryos, the incidence of triploidy has been estimated to range from $0-$ $3.3 \%$, to vary considerably between strains, and to be correlated with the age of the hen (Bloom, 1972, 1974; Mong et al, 1974; Fechheimer, 1981; De Boer et al, 1984). A unique selected line of chickens has been reported by Thorne et al (1991a) with a very high incidence of triploid embryos $(15-20 \%)$. In contrast to mammalian species, both embryonic and post-hatch triploid chickens have been reported (Ohno et al, 1963; Abdel-Hameed and Shoffner, 1971; De Boer et al, 1984; Miyake et al, 1984; Thorne et al, 1991a, b).

In the course of studying gonadal development and differentiation in the domestic fowl, 7 triploid embryos and $12 n / 3 n$ chimera at d 13 of incubation were identified karyotypically and their gonads examined histologically. This report presents a comparison of the histological organization of the gonads of the 3 possible triploid chromosome complements, 3A:ZZZ, 3A:ZWW, and 3A:ZZW, and of a mixoploid (chimera) at an intermediate stage in the development of the chicken embryo.

\section{MATERIALS AND METHODS}

The 651 embryos examined in this study were the result of natural matings between commercial White Leghorn chickens housed in floor pens. The embryos were treated with sources of $\mathrm{H}-\mathrm{Y}$ or $\mathrm{H}-\mathrm{W}$ antigen or antibody between $\mathrm{d} 0-6$ of incubation to determine the effects of the 'sex-determining antigen' on gonadal development in vivo, but no effect was seen (Bonaminio, 1990).

At d 13 of incubation midway through the normal period of development, the eggs were injected with $0.15 \mathrm{ml}$ of a $0.5 \%$ colchicine solution (prepared with $0.85 \%$ $\mathrm{NaCl}$ solution) and incubated for a further $1.5 \mathrm{~h}$. The embryos were sacrificed and a $5-\mathrm{mm}^{3}$ piece of liver was removed and placed on the frosted end of a glass slide with a few drops of EDTA buffer $\left(4 \mathrm{~g} \mathrm{NaCl}, 0.1 \mathrm{~g} \mathrm{KH}_{2} \mathrm{PO}_{4}, 0.1 \mathrm{~g} \mathrm{KCl}, 0.575 \mathrm{~g}\right.$ $\mathrm{Na}_{2} \mathrm{HPO}_{4}$, and $0.1 \mathrm{~g} \mathrm{EDTA}$ in $500 \mathrm{ml}$ distilled water). Another frosted slide was used to grind the liver tissue. The suspension was pipetted into $5 \mathrm{ml}$ EDTA buffer and resuspended. After centrifuging for $10 \mathrm{~min}$ at $1000 \mathrm{rpm}$, the supernatant was discarded and the cells were resuspended by gentle pipetting. Five ml hypotonic solution $(0.075 \mathrm{M} \mathrm{KCl})$ was added, $0.5 \mathrm{ml}$ initially, and then $1.0 \mathrm{ml}$ at a time with agitation. The suspension was allowed to stand for $30 \mathrm{~min}$ at room temperature then centrifuged. The supernatant was discarded and the cells were resuspended in 
a few drops of fixative (3:1, methanol/glacial acetic acid). A total volume of $5 \mathrm{ml}$ fixative was added with agitation. The cells were centrifuged, the supernatant was discarded, and the cells were treated again with fixative. After centrifugation, all but $0.5 \mathrm{ml}$ of the supernatant was discarded and the suspension was dropped onto cold wet slides. The slides were air-dried and stained for $10 \mathrm{~min}$ in a 1:10 Giemsa blood stain/Wright's buffer solution. Five metaphase cells were examined per embryo using a light microscope (magnification 1,000×) to determine the karyotype.

For the histological analysis, the gonads were fixed in $10 \%$ buffered formalin, embedded in Tissue Prep 2 (Fisher Scientific) and sectioned at $4 \mu \mathrm{M}$. The sections were stained in Harris' hematoxylin and eosin A and examined with a light microscope (magnification $400 \times$ ).

\section{RESULTS}

Of the 651 embryos karyotyped, 7 embryos (1.08\%) had a pure triploid chromosome complement and 1 embryo $(0.15 \%)$ was chimeric with a $2 n / 3 n$ karyotype. Five of the embryos were $3 \mathrm{~A}: \mathrm{ZZZ}$ triploids, 1 had a $3 \mathrm{~A}: \mathrm{ZWW}$ chromosome complement, 1 had a $3 \mathrm{~A}: Z Z W$ karyotype, and the chimeric embryo had 2 cell lines, $2 \mathrm{~A}: \mathrm{ZW}$ and 3A:ZZW.

The right and left testes of the 3A:ZZZ triploids had normal testicular organization. Primordial germ cells and epithelial cells were arranged in seminiferous tubules with connective tissue stroma between the tubules.

Normal development of the left and right ovaries was observed in the $3 \mathrm{~A}: \mathrm{ZWW}$ triploid. The left ovary had a distinct cortex and medulla with cords of primordial germ cells in the cortex. The medulla was composed of distended cords and cavities with a few isolated primordial germ cells. The right ovary of the $3 \mathrm{~A}: \mathrm{ZWW}$ triploid embryo lacked a cortex and contained primordial germ cells. This pattern was also observed in normal 2A:ZW embryos.

The 3A:ZZW embryo had a left ovary with a germinal epithelium, cortex, and medulla but few oogonia and epithelial cells in the cortex were arranged in distinct cords or nests. Many oogonia appeared isolated in the cortex. The medulla consisted of medullary cords and distended cords with cavities. The gross morphology of the right ovary of the ZZW embryo was long and thin, resembling a testis. Tubules were visible containing primordial germ cells and epithelial cells throughout the length of the right ovary.

The 2A:ZW/3A:ZZW chimera (94\% 2A:ZW to $6 \% 3 \mathrm{~A}: \mathrm{ZZW})$ had a left ovary with a well-developed cortex with cords of oogonia and epithelial cells and a compact medulla with distended cords and cavities. The right ovary of the $\mathrm{ZW} / \mathrm{ZZW}$ embryo contained structures resembling immature seminiferous tubules.

\section{DISCUSSION}

This is the first report on the gonadal histology of ZZZ triploid embryos. Both right and left testes of these 5 embryos exhibited normal testicular organization at d 13 of development. However, adult ZZZ males, although phenotypically normal, are infertile (Shoffneret al, 1972; Fechheimer, personal communication). Examination 
of the testes in $28 \mathrm{ZZZ}$ triploid chickens found them to be the same from hatching to maturity as diploid males, but grossly abnormal infertile spermatozoa were produced (Thorne et al, 1988). The observations of normal testicular devetopment at $\mathrm{d} 13$ of incubation in the ZZZ triploids examined agrees with the finding in adults .that these birds can advance in development and ultimately reach sexual maturity, although spermatogenesis is impaired.

Embryonic gonads of the ZWW triploid were left and right ovaries exhibiting typical ovarian development. There is no prior report on the gonadal histology of an embryonic ZWW triploid and no hatched ZWW triploid birds have been discovered. According to our observations, the extra set of autosomes and a second $\mathrm{W}$ chromosome do not affect the gonadal differentiation of the female embryo.

The triploid embryo with a $3 \mathrm{~A}: \mathrm{ZZW}$ karyotype had a left ovary that appeared normal in development except that the oogonia and epithelial cells were not arranged in distinct cords. The organization of the right ovary did not resemble the gonadal organization of normal $2 \mathrm{~A}: \mathrm{ZW}$ embryos. The shape of the right ovary, long and cylindrical, was similar to that of an embryonic testis at d 13 of incubation. Structures resembling tubules were organized throughout the right ovary. The greatest number of gonadal histological observations of pure triploids have been those of ZZW adult birds with intersex phenotypes. Frankenhuis et al (1990) reported on 40 commercial layers with intersex characteristics, including 6 karyotyped as ZZW. The right and left gonads of most of the intersexes demonstrated irregularly distributed seminiferous tubules, most with Sertoli cells and spermatogonia. The left gonads also contained a few degenerated follicles. In 41 triploid ZZW birds examined by De Boer (1984), the left gonads contained testicular structures, some exhibiting spermatogenesis, and other parts demonstrating oogenesis. The right gonads contained tubular structures. Thorne et al (1988) studied the development and differentiation of the gonads of $119 \mathrm{ZZW}$ triploid chickens from $1 \mathrm{~d}$ to $2 \mathrm{yr}$ of age. The left gonads at hatching were ovarian-like, became ovotestes by 2 wk post-hatch, and developed testicular tissue from age $3 \mathrm{wk}$ onward. The observations of the left and right ovary of the ZZW triploid at d 13 of development suggest that the left gonad was still ovarian in organization and that testicular development had not yet begun. The right ovary, however, had already begun exhibiting tubular structures as a result of the effect of the $3 \mathrm{~A}: Z Z W$ chromosome constitution on the developing embryo. Indeed, intersex females appear in 1/2,000 females in commercial flocks (Abdel-Hameed and Shoffner, 1971) and begin their lives as apparent females, later exhibiting male secondary sexual characteristics.

The 13-d-old ZW/ZZW chimera had a normal left ovary and a right ovary with some structures resembling immature tubules. The small proportion of $3 \mathrm{~A}: Z Z W$ to $2 \mathrm{~A}: \mathrm{ZW}$ cells $(6 \%$ to $94 \%)$ may explain the relatively normal organization of the right ovary as compared to pure ZZW triploid birds with well-developed tubules in the right gonad. Two adult ZW/ZZW chimeras examined by Thorne et al (1987) were normal fertile hens. The left ovaries and oviduct were typical but each had a partly-developed right oviduct which is not present in normal $2 \mathrm{~A}: \mathrm{ZW}$ females. These findings in adult ZW/ZZW birds are consistent with the gonadal organization and development of the 13-d embryo reported here.

The 3 mechanisms that can produce triploid embryos are diandry (dispermy or fertilization by a diploid sperm) and suppression of meiosis I (MI) or II (MII) in 
oogenesis. The only mechanism that will produce a ZWW triploid is the suppression of MII. Both diandry and MII suppression will produce ZZZ triploids. Since MII suppression should produce an equal number of $\mathrm{ZZ}$ and WW oocytes, the number of ZZZ embryos resulting from MII suppression should approximately equal the number of ZWW embryos arising via this mechanism. The ZZW triploids can arise via both diandry and MI suppression, and the number of ZZW and ZZZ triploids arising via diandry should be equal. On the basis of these mechanisms, Fechheimer (1981) reported from the pooled studies of 147 triploid embryos at 16 to $18 \mathrm{~h}$ of incubation that $75 \%$ are the result of suppression of MII in hens. A further 10 to $15 \%$ of the triploid embryos are the result of MI suppression and the remaining 10 to $15 \%$ are the result of diandry. According to these percentages, the expected percent of ZWW embryos (arising from MII suppression) would be $37.5 \%$, ZZZ (MII suppression and diandry) would be $43.75 \%$, and ZZW (MI suppression and diandry) would be $18.75 \%$. The numbers of ZWW and ZZZ triploid embryos found at $\mathrm{d} 13$ of development differ from the observed number of ZWW and ZZZ embryos at 16 to $18 \mathrm{~h}$ of incubation. Only $14.28 \%$ of the triploid embryos were ZWW triploids versus the expected $37.5 \%$. The observed percentage of ZZZ triploids was $71.43 \%$ versus $43.75 \%$ at 16 to $18 \mathrm{~h}$ of incubation . The percentage of ZZW embryos was $14.28 \%$, close to the observed $18.75 \%$ in early embryos. These differences in the observed percentages at $\mathrm{d} 13$ versus 16 to $18 \mathrm{~h}$ of incubation suggest differential mortality of the 3 triploid embryo types. Further evidence of differential mortality among the 3 triploid genotypes is provided by the data of Thorne et al (1991a). Of 207 triploid embryons karyotyped at $3 \mathrm{~d}$ of incubation, only $22 \%$ of ZWW triploids were alive compared to $71 \% \mathrm{ZZZ}$ and $83 \% \mathrm{ZZW}$. The cases of adult triploid birds reported in the literature are only ZZZ or ZZW birds. The 13-d ZWW embryo described here is the latest developmental stage reported for a ZWW embryo. Bloom (1972) reported that $90 \%$ of the 36 triploid embryos that were observed died at or before $4 \mathrm{~d}$ of incubation, while the remaining $10 \%$ died before hatching. The basis of this selective advantage of one triploid embryo type over another is not clear, although it is possible that it depends on the ratio of sex chromosomes to autosomes.

The other implication of the ratio of sex chromosomes to autosomes in triploids involves the question of sex determination in birds. If birds follow the genic balance model of sex determination, a 1:1 ratio of autosome sets to $\mathrm{Z}$ chromosomes (2A:ZZ or $3 \mathrm{~A}: \mathrm{ZZZ}$ ) would result in a phenotypic female. An intermediate ratio of $3: 2$ (3A:ZZW) results in an intersex phenotype. The $3 \mathrm{~A}: \mathrm{ZWW}$ embryo at $\mathrm{d} 13$ of incubation exhibited female gonadal organization and its ratio of autosomes to $\mathrm{Z}$ chromosomes is 3:1. Unfortunately, triploids do not answer the question of which mechanism is sex-determining in birds. The triploid embryos could be male or female depending on either the autosome to sex chromosome ratio or the presence or absence of a W chromosome. Conclusive evidence would come from $2 \mathrm{~A}: \mathrm{ZZW}$ or $2 \mathrm{~A}: \mathrm{ZO}$ aneuploids but none have been reported.

\section{ACKNOWLEDGMENTS}

Salaries and research support were partially provided by State and Federal Funds appropriated to The Ohio Agricultural Research and Development Center, The Ohio State University, Journal Article No 166-91. 


\section{REFERENCES}

Abdel-Hameed F and Shoffner RN (1971) Intersexes and sex determination in chickens. Science 172, 962-964

Bloom SE (1972) Chromosome abnormalities in chicken (Gallus domesticus) embryos: types, frequencies and phenotypic effects. Chromosoma 37, 309-326

Bloom SE (1974) The origins and phenotypic effects of chromosome abnormalities in avian embryos. Proc 15th World Poult Congr. New Orleans, 316-320

Bonaminio GA (1990) The role of H-W and H-Y antigens in avian and mammalian gonadal differentiation. $\mathrm{PhD}$ dissertation, The Ohio State University, $\mathrm{OH}$

De Boer LEM, De Groen TAG, Frankenhuis MT, Zonneveld AJ, Sallevelt J, and Belterman RHR (1984) Triploidy in Gallus domesticus embryos, hatchlings and adult intersex chickens. Genetica $65,83-87$

Fechheimer NS (1981) Origins of heteroploidy in chicken embryos. Poult Sci 60, 1365-1371

Frankenhuis MT, van Walsum J, De Boer LEM, Dieleman SJ, Misdorp W, van der Valk MA, and Wensing CJG (1990) Triploidy and intersexuality in adult commercial layers. Avian Pathol 19, 3-14

Miyake Y, Syuto B, and Kanagawa H (1984) Gene expression of triploidy in six adult intersexual chickens. Jpn J Vet Res 32, 143-153

Mong SF, Snyder MD, Fechheimer NS, and Jaap RG (1974) The origin of triploidy in chick (Gallus domesticus) embryos. Can J Genet Cytol 16, 317-322

Ohno S, Kittrell A, Christian LC, and Witt GA (1963) An adult triploid chicken (Gallus domesticus) with a left ovotestis. Cytogenetics 2, 42-49

Shoffner RN, Wang N, and Otis JS (1972) Gametogenesis in triploid chickens. Genetica 71 , s59

Thorne MH, Collins RK, and Sheldon BL (1987) Live haploid diploid and other unusual mosaic chickens (Gallus domesticus). Cytogenet Cell Genet 45, 21-25

Thorne MH, Collins RK, Sheldon BL, and Bobr LW (1988) Morphology of the gonads and reproductive ducts of triploid chickens. Proc 18th World Poult Congr. Nagoya, 525-526

Thorne MH, Collins RK, and Sheldon BL (1991a) Triploidy and other chromosomal abnormalities in a selected line of chickens. Genet Sel Evol 23, suppl 1, 212s-216s Thorne MH, Collins RK, Sheldon BL (1991b) Chromosome analysis of early embryonic mortality in layer and broiler chickens. Br Poult Sci 32, 711-722 